\title{
EFFECTIVENESS OF DOTS THERAPY UNDER RNTCP-DOTS STRATEGY IN PAEDIATRIC TB- EXPERIENCE FROM WESTERN INDIA
}

Nikhil Dhananjay Kadam ${ }^{1}$, Sambhaji Shivaji Wagh'2, Uday Chandrapalsingh Rajput ${ }^{3}$, Rajendrakumar Appa Surawashi', Supriya Rode 5 , Sandeep Jagdale6, Suhas Khaire ${ }^{7}$, Shailesh Rathod ${ }^{8}$

${ }^{1}$ Senior Resident, Department of Neurology, Sir JJ Group of Hospitals, Mumbai.

${ }^{2}$ Associate Professor, Department of Paediatrics, Government Medical College, Miraj.

${ }^{3}$ Associate Professor, Department of Paediatrics, B. J. Medical College, Pune.

${ }^{4}$ Incharge, DOTS Centre, Miraj.

5 Private Practitioner, ENT, Thane.

${ }^{6}$ Private Practitioner, Paediatrics, Pune.

${ }^{7}$ Senior Resident, Department of Endocrinology, TNMC and Nair Hospital, Mumbai.

8Private Practitioner, Paediatrics, Parbhani.

ABSTRACT
BACKGROUND
Though estimated one million new cases of tuberculosis occur in children worldwide each year, paediatric TB has not been given
the same priority as its adult counterpart. TB in children needs to be identified promptly and managed effectively. The DOTS
strategy appears to be highly effective for paediatric TB, as reported by studies from all over the world. The aim of this study is to
evaluate the efficacy of the DOTS strategy in the management of paediatric TB patients and factors affecting the outcome of
paediatric TB patients.

\section{MATERIALS AND METHODS}

A prospective study is conducted from December 2010 to August 2011 at a tertiary care paediatric institute from western India. The patients presenting with signs and symptoms of tuberculosis were diagnosed with RNTCP guidelines and put on DOTS treatment. The patients on DOTS but presenting with relapse, treatment failure and defaulters were also included. At the end of treatment, the outcome was assessed in terms of treatment completion, cure rate, failure rate, relapse and drug resistance.

\section{RESULTS}

Of the total 104 patients, the treatment outcome was assessed in 96 patients. $81.73 \%$ completed treatment, $10.57 \%$ were declared cured, $1.92 \%$ patients cured with extending primary regimen, $4.80 \%$ defaulted and one child died. High prevalence of TB was seen in females (62.5\%) than males (37.5\%). There is high rate of treatment completion and cure in extrapulmonary TB (95.92\%). There are more defaulters in pulmonary TB (7.23\%). There is no significant difference in treatment completion in pulmonary and EPTB. $(\mathrm{P}>0.05)$.

\section{CONCLUSION}

The DOTS strategy appears to have improved TB treatment success. Sex, nutrition and type of tuberculosis have significant impact on outcome of treatment. The present definition of cure given by RNTCP is with reference to sputum positive cases only and cannot be applied to paediatric cases. So, the definition should be revised to include guidelines for cure in paediatric TB.

\section{KEYWORDS}

Paediatric TB, RNTCP, DOTS, Treatment Success.

HOW TO CITE THIS ARTICLE: Kadam ND, Wagh SS, Rajput UC, et al. Effectiveness of DOTS therapy under RNTCP-DOTS strategy in paediatric TB- Experience from western India. J. Evolution Med. Dent. Sci. 2017;6(58):4316-4320, D0I: 10.14260/Jemds/2017/933

\section{BACKGROUND}

Tuberculosis is still one of the deadliest diseases in the world killing nearly two million people every year. Young children carry the greatest burden of the tuberculosis disease. They are most likely to develop disease after infection and are most likely to develop extrapulmonary and severe disseminated disease than adults. Infected children represent

Financial or Other, Competing Interest: None.

Submission 14-06-2017, Peer Review 08-07-2017,

Acceptance 14-07-2017, Published 20-07-2017.

Corresponding Author:

Dr. Nikhil Dhananajay Kadam,

Flat No. 7, Pandurang Apartment,

Near Patane Gas Agency,

Chandani chowk, Sangli, Maharashtra.

E-mail:drnikhildkadam@gmail.com

DOI: $10.14260 /$ jemds $/ 2017 / 933$ pool from which a large proportion of future cases of adult TB will arise. In addition, childhood TB is a sentinel event indicating ongoing transmission of TB within communities. Of the 9 million annual TB cases, about 1 million (11\%) occur in children under 15 years of age. Of these childhood cases, $75 \%$ occur annually in 22 high burden countries that together account for $80 \%$ of the world's estimated incident cases. ${ }^{1}$ Overall, the relative prevalence of new smear-positive TB was $5 \%$ in the paediatric age as against $95 \%$ in adults and overall the number of smear-negative cases was relatively higher in the former than the latter ( $56 \%$ vs. $40 \%$, respectively). ${ }^{2}$ Management of TB in children is challenging owing to paucibacillary nature of the disease, difficulty in sputum collection, the poor sensitivity of currently available diagnostic modalities and the absence of a gold standard for diagnosis.

"I have no business to live this life if I cannot eradicate this horrible scourge from the mankind" - Robert Koch 
(1882) delivering a lecture at Berlin University on his discovery of tuberculosis bacilli. ${ }^{3}$

Excellent success rates have been achieved for adult TB patients worldwide with the WHO-recommended DOTS strategy, including India where it is under Revised National Tuberculosis Control Programme (RNTCP). However, there is scarcity of reported data on paediatric TB outcome and factors associated with it from western and central Indian states. The aim of this study is to evaluate the efficacy of the DOTS strategy and factors affecting the outcome of paediatric TB patients.

\section{MATERIALS AND METHODS}

A prospective hospital-based study conducted at Department of Paediatrics (OPD/Ward/PICU) and DOTS centres of Government Medical College and Hospital over the period of two years (from December 2010 to November 2012).

\section{Study Design}

Descriptive study.

\section{Inclusion Criteria}

1. All newly diagnosed cases of Tuberculosis from $0-12$ years of age.

2. Those children who were already diagnosed with TB and on DOTS but presenting with relapse, treatment failure and defaulter.

\section{Exclusion Criteria}

Children with Tuberculosis already on antitubercular treatment were excluded from the study.

A detailed history including demographic profile and clinical examination was carried out for each case as outlined in the proforma (Appendix A). Diagnosis was made based on RNTCP guidelines and accordingly child was categorised and then put on DOTS. Child was attending paediatric TB clinic for followup both during intensive and continuation phase and sputum status where applicable. During followup special emphasis was given on relevant history and detailed physical examination, compliance and adverse events to drugs if any. At the end of treatment, child was assessed for outcome clinically as weight gain, clinical improvement, lymph node size and based on investigations such as CXR, CT, USG if required.

\section{Ethical Clearance}

Ethical clearance has been obtained from institutional local ethical committee.

\section{Informed Consent}

Written informed consents of the parents of children enrolled in the study were taken according to proforma (Appendix B).

\section{Statistical Analysis}

Results were analysed by using appropriate statistical tests. Mean, averages, standard deviations were calculated for various parameters and risk factors. Fisher's exact test was used for qualitative comparative data. A ' $p$ ' value less than 0.05 was taken as statistically significant.

\section{Definition of forms of TB and Treatment Outcome in Childhood Tuberculosis ${ }^{1}$}

Pulmonary TB, sputum smear-positive: The criteria are: Two or more initial sputum smear examinations positive for acidfast bacilli; Or One sputum smear examination positive for acid-fast bacilli plus CXR abnormalities consistent with active pulmonary $\mathrm{TB}$, as determined by a clinician; Or One sputum smear examination positive for acid-fast bacilli plus sputum culture positive for M. tuberculosis. Adolescents, or children of any age with complicated intrathoracic disease, are more likely to have sputum smear-positive pulmonary TB.

\section{Pulmonary TB, Sputum Smear-Negative}

It is a case of pulmonary TB that does not meet the above definition for smear-positive pulmonary TB. In keeping with good clinical and public health practice, diagnostic criteria for sputum smear-negative pulmonary TB should include: At least three sputum specimens negative for acid-fast bacilli; and radiological abnormalities consistent with active pulmonary TB; and 'No response' to a course of broadspectrum antibiotics; and decision by a clinician to treat with a full course of anti-TB chemotherapy.

\section{Extrapulmonary TB}

Children with only extrapulmonary TB should be classified under this case definition. Children who have both pulmonary and extrapulmonary TB should be classified under the case definition of pulmonary TB.

\section{Cured}

Patient who is sputum smear-negative in the last month of treatment and on at least one previous occasion.

\section{Treatment Failure}

Patient who is sputum smear-positive at 5 months or later after starting.

\section{Completed Treatment}

Patient who has completed treatment but who does not meet the criteria to be classified as cured or treatment failure.

\section{Died}

Patient who dies for any reason during the course of treatment.

\section{Defaulted}

Patient whose treatment was interrupted for 2 consecutive months or more.

As per the joint statement of the Central TB Division, Directorate General of Health Services, Ministry of Health and Family Welfare, and experts from Indian Academy of Paediatrics, ${ }^{4}$ clinical or symptomatic improvement is to be assessed at the end of the intensive phase of treatment and at the end of treatment. Improvement should be judged by absence of fever or cough, decrease in the size of lymph node(s), weight gain. Radiological improvement is to be assessed by Chest X-ray examination in all smear-negative pulmonary TB cases at the end of treatment.

\section{RESULTS}

In our study, a total of 104 patients were enrolled. 


\section{Demographic Variables}

Out of 104, 39 were male and 65 were female children. The age groups were as follows: 2 patients were less than 1 year, 38 patients were between 1 - 5 years, 30 patients were between 5 - 10 years and 34 patients were between $10-12$ years age group. 71 were Hindus, 32 were Muslims and 1 was Christian.

\section{Clinical Variables}

In the present study, most common presenting symptoms were fever (75\%), chronic cough (>3 weeks) $(67.30 \%)$, loss of appetite $(63.46 \%)$, not gaining weight $(50 \%)$. The most common clinical signs found were abnormal chest sounds (38.46\%), lymphadenopathy at different sites or generalised (26.92\%). $35.57 \% \%$ of the patients had history of contact with tuberculosis patients. 12 patients were HIV reactive. 55 cases $(52.89 \%)$ were diagnosed to have pulmonary tuberculosis based on mainly the chest X-ray findings. Sputum or gastric lavage positivity was not encountered in any patient. 49 cases (47.11\%) were having extrapulmonary forms of tuberculosis. Types of extrapulmonary TB were lymph node TB in 27 (55.10\%), Abdominal TB in 7 (14.28\%), pleural effusion in 6 cases (12\%), disseminated in $6(12 \%)$, neurotuberculosis in 3 (6\%). 97 patients were put under category I (93.23\%), 7 patients were put under category II $(6.67 \%)$ of RNTCP-DOTS regimen.

\section{Treatment Response and Outcome Variables}

Of the total 104 patients enrolled in the study, the treatment outcome could be obtained only for 98 patients as five patients ( 3 male, 2 female) defaulted. One patient died before treatment completion. The study revealed mean weight gain of $2.5 \mathrm{~kg}$ (SD-2). Chest x-ray clearance was seen as Complete clearance in $11(14.86 \%)$ of the patients. Moderate to significant clearance was noted in $36(48.65 \%)$ of patients. Mild clearance was seen in $20(27.02 \%)$ of patients and no change in 1 case only. In this study, more than half of the patients of lymph node TB i.e. 15 (55.56\%) were showing complete reduction in the lymph node size. 7 (25.92\%) patients were showing fifty percent reduction in the lymph node size. $81.73 \%(85 / 104)$ of the study population completed treatment, $17.30 \%$ (18/104) defaulted and one child died.

\begin{tabular}{|c|c|c|c|c|}
\hline Characteristics & $\begin{array}{c}\text { Total } \\
\text { Number } \\
\text { of Cases }\end{array}$ & $\begin{array}{c}\text { Total Number } \\
\text { of Unsuccessful } \\
\text { Outcomes* }\end{array}$ & $\begin{array}{c}\mathrm{X}^{2} \\
\text { value }\end{array}$ & $\begin{array}{c}P \\
\text { value }\end{array}$ \\
\hline \multicolumn{5}{|l|}{ Sex } \\
\hline Female & 65 & 14 & \multirow{2}{*}{0.87} & \multirow{2}{*}{$<0.05$} \\
\hline Male & 39 & 5 & & \\
\hline \multicolumn{5}{|l|}{ TB type } \\
\hline Pulmonary & 55 & 8 & \multirow{2}{*}{0.75} & \multirow{2}{*}{$<0.05$} \\
\hline Extrapulmonary & 49 & 11 & & \\
\hline \multicolumn{5}{|l|}{ Nutrition } \\
\hline Normal & 53 & 6 & \multirow{2}{*}{1.64} & \multirow{2}{*}{$<0.05$} \\
\hline Malnourished & 51 & 13 & & \\
\hline
\end{tabular}

*-unsuccessful outcomes are defined as defaulters, death or failures.

\begin{tabular}{|c|c|c|c|c|}
\hline Type of EPTB & $\begin{array}{c}\text { Mal- } \\
\text { nourished }\end{array}$ & Normal & Total & P value \\
\hline & $\mathrm{n}=26(\%)$ & $\mathrm{n}=23(\%)$ & $\mathrm{n}=49$ & \\
\hline Disseminated & $8(30.77 \%)$ & $1(4.32 \%)$ & 9 & 0.0256 \\
\hline $\begin{array}{c}\text { Neuro- } \\
\text { tuberculosis }\end{array}$ & & & & \\
\hline Other Forms* & $18(69.23 \%)$ & $\begin{array}{c}22 \\
(95.65 \%)\end{array}$ & 40 & \\
\hline \multicolumn{5}{|c|}{$\begin{array}{c}\text { Table 2. Relation between Nutrition } \\
\text { and Severe Forms of Tuberculosis }\end{array}$} \\
\hline
\end{tabular}

EPTB- extrapulmonary tuberculosis

*-Include abdominal TB, Lymph node TB, Osseous TB

\begin{tabular}{|c|c|c|c|c|}
\hline $\begin{array}{c}\text { Treatment } \\
\text { Outcome }\end{array}$ & $\begin{array}{c}\text { Pulmonary } \\
\text { TB patients } \\
\text { (\%) }\end{array}$ & $\begin{array}{c}\text { Extra } \\
\text { Pulmonary } \\
\text { TB patients } \\
(\%)\end{array}$ & $\begin{array}{c}\text { Total } \\
(\%)\end{array}$ & $\begin{array}{c}P \\
\text { value }\end{array}$ \\
\hline $\begin{array}{l}\text { Treatment } \\
\text { completed } \\
\text { and cured }\end{array}$ & $\begin{array}{c}47 \\
(85.45 \%)\end{array}$ & $\begin{array}{c}38 \\
(77.55 \%)\end{array}$ & $\begin{array}{c}85 \\
(81.73 \%)\end{array}$ & 0.269 \\
\hline Defaulters & $\begin{array}{c}8 \\
(14.54 \%)\end{array}$ & $\begin{array}{c}10 \\
(20.40 \%)\end{array}$ & $\begin{array}{c}18 \\
(17.30 \%)\end{array}$ & \\
\hline Death & 0 & $\begin{array}{c}1 \\
(2.04 \%)\end{array}$ & $\begin{array}{c}1 \\
(0.96 \%)\end{array}$ & \\
\hline Total & $\begin{array}{c}55 \\
(52.88 \%)\end{array}$ & $\begin{array}{c}49 \\
(47.11 \%)\end{array}$ & 104 & \\
\hline \multicolumn{5}{|c|}{$\begin{array}{l}\text { Table 3. Distribution of Patients According to } \\
\text { Treatment Outcome/Defaulters and Type of TB }\end{array}$} \\
\hline
\end{tabular}

\section{DISCUSSION}

In the present study, we studied the paediatric tuberculosis cases prospectively to document the clinical improvement after treatment and tried to analyse factors influencing the outcome. As there is paucity of cases of sputum positive pulmonary $\mathrm{TB}$ in children, still pulmonary form of TB predominated than extrapulmonary forms of TB which formed almost half of our study population (Arora $\mathrm{V} \mathrm{K}$ et al, 5 Sreshtha $\mathrm{S}$ et al, ${ }^{6}$ Cherry Lyn et $\mathrm{al}^{7}$ ). The treatment outcome in paediatric TB is gauged according to the clinical parameters which are different than the adult counterparts.

Most of the patients were female similar to studies done by Sharma $\mathrm{S}$ et al, ${ }^{8} \mathrm{C}$ K Indumathi et al. ${ }^{9}$ The high prevalence of cases in females in our study could be explained by the fact that most of our study population belonged to lower socioeconomic class where the females exposed to the infection are more prone to develop the disease due to either poor nutritional status or poor immunity. The poor BCG vaccination status in females might also be a responsible factor for acquiring the infection. Also, the gender and unsuccessful outcome stand statistically significant. (Table 1 ). In the present study, mean age of presentation (6.9 years, SD $=3.7$ ) is younger than other studies in tertiary care institutes (CK Indumathi et al, ${ }^{9}$ Shivanandan $S$ et al, ${ }^{10}$ Shrestha $S$ et al ${ }^{11}$ ), may be because of more number of malnourished children in this study who might have presented earlier in the disease process. The nutrition has significant impact on the outcome of TB. The unsuccessful outcomes are more in the malnourished group which is statistically significant (Table 1). Most of the severely malnourished children develop severe forms of tuberculosis which is statistically significant. $(\mathrm{p}<0.05)$. (Table 2). This supports the fact that TB and Malnutrition form a vicious cycle. 
Malnutrition adversely affects the host's defence mechanism by suppressing cell mediated response to the infection. In malnourished children, there is a higher risk of a localised lesion to become progressive or generalised disseminated tuberculosis, because of poor immune response to infection. Similar results were obtained from studies done in developing countries. (Cherry Lyn et al, 7 Shrestha $S$ et al,11 Sushmabhai $S$ et al ${ }^{12}$ ).

In this study, $81.73 \%(85 / 104)$ of the study population completed treatment, $17.30 \%(18 / 104)$ defaulted and one child died. We observed a cure rate of $11.34 \%$ (11/97) for new cases and $28.57 \%$ (2/7) for re-treatment cases, but the treatment completion rate was significantly higher for new $87.63 \%(85 / 97)$ and $42.86 \%$ for re-treatment cases (3/7). Similar success rates were obtained by studies done elsewhere in other parts of India, Nepal by Sharma S et al,13 Kabra et al,14 A. D. Harries et al,15 S. Sushama Bai et al. ${ }^{12}$ According to RNTCP, cure is defined only for sputum positive pulmonary $\mathrm{TB}$, since most of the paediatric patients have sputum negative TB and extrapulmonary TB the outcome of treatment was declared as treatment completed. However, as the symptoms of the patients improved they can be considered apparently cured. The WHO has reported cure rates of $80 \%$ and default rates of $10 \%$ among more than 30 million TB patients treated with the DOTS strategy. ${ }^{16}$ The lower treatment failure rate in our study might be due to good treatment adherence and low prevalence of MDR-TB in our area.

In our study, there is high rate of treatment completion and cure in pulmonary TB. (85.45\%). There are more defaulters in extrapulmonary TB $(20.40 \%)$ (Table 3). The difference for unsuccessful outcomes is statistically significant (Table 1). This could be due to high rate of HIV coinfection in these group of patients,[17] which may decrease the treatment success and increase mortality. Average weight gain of $2.5 \mathrm{~kg}$ in our study is comparable to the study done by M Vasantha ${ }^{18}$ which revealed mean change in weight of $3.2 \mathrm{~kg}$. The weight gain may also be because of the growth occurring normally in children. In our study, the response to treatment was significant in lymph node TB group and more than half the affected population showed complete clearance. The reason for good response to short course of chemotherapy may be the organism load in children with isolated peripheral TB lymphadenitis is low, but no randomised studies have been performed to support this. ${ }^{19}$

In our study, we did not encounter the drug resistant cases or the cases might be admixed with the defaulter population. The significant rate of treatment completion, cure and evidence of supportive clinical and laboratory improvement strongly establishes role of DOTS in paediatric population. Since 1993, the WHO has recommended the DOTS strategy to help national governments to treat patients and prevent the spread of TB by providing quality assured drugs under the direct observation of health workers. ${ }^{4,20,21}$ We recommend that DOTS is a highly efficacious strategy in the treatment of childhood tuberculosis.

\section{CONCLUSION}

Childhood tuberculosis still continues to be a major health problem in children of 1-5 years of age who are undernourished and belonging to low socioeconomic status. The high prevalence of cases in females is also alarming for the socioeconomic structure and growth. Thus, improving the socioeconomic conditions and proper treatment of adult TB which are the source of infection to children will go a long way in preventing childhood TB and protecting children who are the future of our country. The present definition of cure given by RNTCP is with reference to sputum positive cases only and cannot be applied to paediatric cases where most of the cases are sputum negative pulmonary cases and extrapulmonary cases. Thus, the definition should be revised to include guidelines for cure in paediatric TB. The DOTS strategy appears to be highly effective for paediatric TB.

Further research into the epidemiology, immune mechanisms, diagnosis, treatment and prevention of childhood tuberculosis is urgently needed. Advances in our understanding of tuberculosis in children would provide insights and opportunities to enhance efforts to control this disease.

\section{Limitations of the Study}

Our study focuses on limited parameters which influence the treatment outcome in paediatric TB. There are number of other parameters like BCG status, HIV coinfection, grades of malnutrition, TB contact history which should be studied in detail to broaden the spectrum. Also, multicentre studies taking heterogeneous population is highly welcome.

\section{REFERENCES}

[1] Guidance for national tuberculosis programmes on the management of tuberculosis in children WH0/HTM/TB/2006.371. Available from: URL: http://www.who.int/child_adolescent_health/docume nts/htm_tb_20 06_3 71/en/index.html.

[2] RNTCP: Implementation status and activities in 2010, changes in RNTCP guidelines ch.3 In: TB India 2011 annual status report. Central TB division, directorate general of health services. New Delhi 2010;82.

[3] Koch R. Die aetiologie der tuberculose. Berl Klin Wochenschr 1882;19:221-30.

[4] Chauhan LS, Arora VK. Management of pediatric tuberculosis under the revised national tuberculosis control programme (RNTCP). Indian Pediatr 2004;41(9):901-5.

[5] Arora VK, Gupta R. Directly observed treatment for tuberculosis. Indian J Pediatr 2003;70(11):885-9.

[6] Shrestha S, Bichha RP, Sharma A, et al. Clinical profile of tuberculosis in children. Nepal med coll J 2011;13(2):119-22.

[7] Lyn CPP, Gatchalian SR. Clinical profile of culture proven tuberculosis cases among Filipino children aged 3 months to 18 years. PIDSP Journal 2002;6(1):13-23.

[8] Sharma S, Sarin R, Khalid UK, et al. The DOTS strategy for treatment of paediatric pulmonary tuberculosis in South Delhi, India. Int J Tuberc Lung Dis 2008;12(1):74-80.

[9] Indumathi CK, Prasanna KK, Dinakar C, et al. Intermittent short course therapy for pediatric tuberculosis. Indian Paediatr 2010;47(1):93-6.

[10] Sivanandan S, Walia M, Lodha R, et al. Factors associated with treatment failure in childhood tuberculosis. Indian Paediatr 2008;45(9):769-71. 
[11] Shrestha S, Marahatta SB, Poudyal P, et al. Clinical profile and outcome of childhood TB at Dhulikhel hospital. J Nepal paediatrics soc 2011;31(1):7-11.

[12] Sushamabai S, Devi LR. Clinical spectrum of tuberculosis in BCG vaccinated children. Indian Pediatrics 2002;39:458-62.

[13] Sharma S, Sarin R, Khalid UK, et al. Clinical profile and treatment outcome of tuberculous lymphadenitis in children using DOTS strategy. Indian J Tuberc 2010;57(1):4-11.

[14] Kabra SK, Lodha R, Seth V. Category based treatment of tuberculosis in children. Indian Paediatr 2004;41(9):927-37.

[15] Harries AD, Hargreaves NJ, Graham SM, et al. Childhood tuberculosis in Malawi: nationwide casefinding and treatment outcomes. Int J Tuberc Lung Dis 2002;6(5):424-31.

[16] Rangsima L, Amornrat A, Sriprapa N, et al. Childhood TB epidemiology and treatment outcomes in Thailand: a TB active surveillance network, 2004 to 2006. BMC Infect Dis 2008;8:94.
[17] Esmael A, Tsegaye G, Wubie M, et al. Treatment outcomes of tuberculosis patients in debre markos referral hospital, north west Ethiopia a five year retrospective study. IJPSR 2014;5(4):1500.

[18] Vasantha M, Gopi PG, Subramani R. Weight gain in patients with tuberculosis treated under directly observed treatment short-course (DOTS). Indian J Tubrc 2009;56(1):5-9.

[19] World Health Organization. Treatment of tuberculosis: guidelines for national programmes. Geneva, Switzerland: WHO 1993:1-43.

[20] Ministry of Health \& Family Welfare. Managing the revised national tuberculosis control programme in your area-a training course. Modules 1-4. New Delhi, India: Central TB division, directorate general health services 2001:1-138.

[21] World Health Organization. Global tuberculosis control: surveillance, planning, financing. WHO report 2006. WHO/HTM/TB 2006. 362. Geneva, Switzerland: WHO, 2006. 